\title{
Comparison of deep and superficial abdominal muscle activity between experienced Pilates and resistance exercise instructors and controls during stabilization exercise
}

\author{
Ji-Hyun Moon', Sang-Min Hong ${ }^{2}$, Chang-Won Kim³ ${ }^{3}$ Yun-A Shin ${ }^{4, *}$ \\ 'Department of Kinesiologic Medical Science, Graduate School, Dankook University, Cheonan, Korea \\ ${ }^{2}$ Department of Kinesiology, College of Education, Dongguk University, Seoul, Korea \\ ${ }^{3}$ Hanmam plus Sports Medicine Institute, Hanmam Plus Hospital, Seoul, Korea \\ ${ }^{4}$ Department of Exercise Prescription \& Rehabilitation, College of Sports Science, Dankook University, Cheonan, Korea
}

Pilates and resistance exercises are used for lumbar stabilization training. However, it is unclear which exercise is more effective for lumbar stabilization. In our study, we aimed to compare surface muscle activity and deep muscle thickness during relaxation and spinal stabilization exercise in experienced Pilates and resistance exercise instructors. This study is a retrospective case control study set in the Exercise Prescription Laboratory and Sports Medicine Center. The participants included Pilates instructors (mean years of experience, $3.20 \pm 1.76 ; n=10$ ), resistance exercise instructors (mean years of experience, $2.53 \pm 0.63$; $n=10)$, and controls $(n=10)$. The participants performed 4 different stabilization exercises: abdominal drawing-in maneuver, bridging, roll-up, and one-leg raise. During the stabilization exercises, surface muscle activity was measured with electromyography, whereas deep muscle thickness was measured by ultrasound imaging. During the 4 stabilization exercises, the thickness of the transverse abdominis ( $\operatorname{Tr} A)$ was significantly greater in the Pilates-trained group than the other 2 other groups. The internal oblique $(\mathrm{IO})$ thickness was significantly greater in the Pilates- and resistance-trained group than the control group, during the 4 exercises. However, the surface muscle activities were similar between the groups. Both Pilates and resistance exercise instructors had greater activation of deep muscles, such as the $\operatorname{Tr} A$ and 10 , than the control subjects. Pilates and resistance exercise are both effective for increasing abdominal deep muscle thickness.

Keywords: Transversus abdominis, Obliquus internus abdominis, Ultrasonography, Electromyography, Exercise

\section{INTRODUCTION}

Back pain is very common and affects $80 \%$ the population at some point in their life (da Fonseca et al., 2009). Moreover, back pain can easily relapse or lead to chronic pain. Frequent and prolonged back pain inhibits physical activities, leading to a decrease in flexibility, range of motion, muscle strength and endurance, myoatropy, and paraspinal muscle cross-sectional area (Adams and Roughley, 2006).

Various rehabilitation and exercise programs have been devel- oped to increase lower back muscle strength and correct imbalanced muscle strength in patients with back pain (Sertpoyraz et al., 2009). Many treatment methods that strengthen the superficial muscles, including the hamstrings and extensors, have been suggested to decrease back pain (Gladwell et al., 2006; Monfort-Pañego et al., 2009). In addition, previous studies have reported that abdominal strength is also important not only for the prevention and treatment of back pain, but also for improving trunk movement and stability. Thus, abdominal exercises have been widely used in rehabilitation or exercise programs for ath-
${ }^{*}$ Corresponding author: Yun-A Shin

Department of Exercise Prescription \& Rehabilitation, College of Sports Science, Dankook University, 119 Dandae-ro, Dongnam-gu, Cheonan 330-714, Korea Tel: +82-41-550-3831, Fax: +82-41-550-3831, E-Mail: shinagel@dankook.ac.kr Received: May 12, 2015 / Accepted: June 4, 2015
This is an Open Access article distributed under the terms of the Creative Commons Attribution Non-Commercial License (http://creativecommons.org/licenses/by-nc/3.0/) which permits unrestricted non-commercial use, distribution, and reproduction in any medium, provided the original work is properly cited. 
letes and normal individuals (Stevens et al., 2007).

However, trunk muscles are classified into 2 groups; superficial muscles that are part of the global muscle system and include the rectus abdominis (RA) and the external oblique (EO), and deep muscles that are part of the local muscle system and include the transverses abdominis ( $\operatorname{Tr} A$ ), the multifidus and the internal oblique (IO) (Bergmark, 1989). Recent studies have reported that lumbar stabilization exercises, including contraction of the $\operatorname{Tr} A$, IO, and the multifidus, increase spinal stability and are more effective than other treatments such as abdominal exercises that decrease pain and functional abnormality in terms of neuromuscular control and improvement (Hayden et al., 2005; Macedo et al., 2009).

Pilates is an exercise that includes basic movements and focuses on strengthening the abdomen for spinal support. Pilates has been used for back pain rehabilitation and athletic conditioning because it reportedly activates the transverse abdominis $(\operatorname{Tr} A)$ and the internal obliques (IO), which stabilize the spine (Bernardo, 2007). Indeed, Critchley et al. (2011) reported that the TrA and the IO were significantly thickened during Pilates or resistance exercises, relative to resting conditions. Furthermore, increases in $\operatorname{TrA}$ and IO thickness after resistance training have been shown (Critchley et al., 2011), and the $\operatorname{Tr} A$ and the IO thickness of weightlifters is greater than average controls (Sitilertpisan et al., 2011). Thus, Pilates and resistance exercise both increase the strength and endurance of the abdominal muscles, as well as the thickness of the deep muscles, but it is unclear which exercise is more effective in stabilizing the spine.

Various spinal stabilization exercises have been used, including bridging, one-leg raise (Stevens et al., 2007; Waddell et al., 1992), abdominal drawing-in maneuver (ADM) (Teyhen et al., 2005), and crunch (Ekstrom et al., 2007). However, most studies that have examined the effect of lumbar stabilization merely investigated deep muscle activity and thickness using ultrasound (John and Beith, 2007; McMeeken et al., 2004) or assessed the changes in muscle activity using electromyography (EMG) (Hibbs et al., 2011; Sternlicht and Rugg, 2003). Importantly, Hodges and Moseley (2003) suggested that the global and local muscle systems need to work synergistically to activate the deep muscles and ensure efficient lumbar spine stabilization and muscle function. Thus, consideration of both ultrasound deep muscle scans and surface EMG would be helpful to compare the effect of Pilates and resistance exercise on lumbar stabilization (Jeong et al., 2006).

In the present study, we aimed to compare surface muscle activ- ity and deep muscle thickness during relaxation and spinal stabilization exercise in experienced Pilates and resistance exercise instructors, relative to control subjects. We tested the following hypotheses: (1) surface muscle activity during stabilization exercises would be greater in resistance and control groups, compared to a Pilates group, (2) a Pilates trained group would have a greater deep muscle thickness during stabilization exercise, compared to the other groups, and (3) Pilates exercise is effective for lumbar stabilization.

\section{MATERIALS AND METHODS}

\section{Subjects and experiment design}

The subject population included 10 experienced female Pilates instructors with more than 6 months of instructor experience (mean years of experience, 3.20 \pm 1.76 ) and a Canada Stott Pilates instructor certificate (mean age, 26.50 $\pm 4.22 \mathrm{yr}$ ), 10 experienced female resistance exercise instructors with more than 6 months of instructor experience (mean years of experience, $2.53 \pm 0.63$ ) and a Sports for All instructor certificate with specialization in resistance exercise (mean age, $24.50 \pm 1.65 \mathrm{yr}$ ), and 10 females controls who were ordinary individuals, had sedentary lifestyles, and had not regularly exercised in the last 6 months (mean age, 25.60 1.84 yr). To maintain consistency between groups and exclude the influence of obesity, which might affect ultrasound and EMG results, individuals with a body mass index (BMI) of 18.5-24.9 (normal range) were selected (John and Beith, 2007). Potential participants were excluded if they were aged $<20 \mathrm{yr}$, had previous spinal or abdominal surgery, had lower back pain in the last two years, had visible scoliosis, had neuromuscular disorders, or were pregnant. The Institutional Ethics Committee of Physical Education of Dankook University approved the study.

\section{Physical examination}

Four different stabilization exercises (ADM, bridging, crunch, and one-leg raise) were used in the present study. One investigator performed all of the procedures and tasks with each subject to ensure uniformity. All of the exercises were demonstrated by an experienced physical therapist with training in the ADM method. Following collection of basic anthropocentric measurements and familiarization of the subject with the equipment and tasks, surface muscle maximal voluntary isometric contraction (MVIC) was performed for normalization. Superficial stabilizer and deep stabilizer muscle activities were then evaluated at rest and during ADM, bridging, crunch, and one-leg raise stabilization exercises. 
All of the exercises were executed in the supine position and were performed 2 times, with 2-3 min of rest in between. The order of the exercises was randomized.

\section{EMG measurement}

EMG activity was recorded using 1-cm diameter silver/silver chloride surface electrodes, which were placed with a center-to-center spacing of $2.2 \mathrm{~cm}$ ( $\mathrm{Ng}$ et al., 1998). The EMG was sampled at $1,000 \mathrm{~Hz}$, with a width of $8-500 \mathrm{~Hz}$ using a Noraxon Telemyo 2400T 8-channel remote control instrument. The sensor locations were marked on the skin based on the Surface ElectoMyoGraphy for the Non-Invasive Assessment of Muscle (SENIAM) guidelines. The subject's skin was wiped and cleaned, and 2 electrodes were placed parallel to the muscle fibers $2 \mathrm{~cm}$ apart. A test was performed to ensure that the EMG signals were recorded when the muscles were moved as well as to determine the noise level, baseline adjustments, and displacement due to joint movement. The MVIC of the rectus abdominis (RA) and external oblique (EO) muscles, and their activity during muscular work were measured (Table 1). Three 5-sec-long MVICs were performed with verbal encouragement, with 5 min of rest in between. The largest EMG value was used as the MVIC.

\section{Deep muscle thickness}

An ultrasound machine (Sonoace 6000c, Korea) was used to measure the thickness of the $\operatorname{Tr} A$ and IO. A rehabilitation specialist performed all of the measurements to avoid individual evaluator differences. The ultrasound scans were obtained using a 5.5$\mathrm{cm}, 5-12 \mathrm{MHz}$ linear transducer (M12L linear probe), and were recorded at $10 \mathrm{MHz}$. The brightness of the screen was 55. The abdominal midaxillary line between the right iliac crest and inferior angle of the costal bone was investigated in all subjects by placing the transducer vertically to obtain clear images of the external muscles (Teyhen et al., 2005). The area was marked with a marker to allow for repositioning of the transducer in the same location. Previous researchers have found the inter-image and inter-rater reliability to have intraclass correlation coefficients of $>0.93$, using the same measurement technique to assess the ADM (Springer et al., 2006; Teyhen et al., 2005). The depth was also adjusted until the muscle layer comprised approximately 40$50 \%$ of the ultrasound image. As the $\operatorname{Tr} A$ is recruited during inhalation (Hodges and Gandevia, 2000), images were obtained at the end of exhalation in each posture. Resting abdominal muscles were measured with the subject lying straight without bending their knees (no tension in the abdominal area). All of the postures

Table 1. Stabilization exercises

\begin{tabular}{|c|c|c|}
\hline Exercise & Procedures & \\
\hline Resting & $\begin{array}{l}\text { The subjects were asked to lie down in the supine position. Their right abdominal muscles were measured } \\
\text { while they were resting (no tension in the abdominal area). }\end{array}$ & \\
\hline \multirow[t]{2}{*}{ ADM (imprint) } & $\begin{array}{l}\text { The subjects were asked to lie down in the supine position with their upper back on a table and their feet on } \\
\text { the floor. Before they performed the ADM, they were instructed to palpate their abdominal muscle just anteri- }\end{array}$ & \\
\hline & $\begin{array}{l}\text { omedially to their anterior super iliac spine, identify the muscle contraction when they coughed, and contract } \\
\text { this muscle. }\end{array}$ & \\
\hline \multirow[t]{2}{*}{ Bridging } & $\begin{array}{l}\text { The subjects were asked to lie down in the supine position with their arms at their sides and their knees } \\
\text { forming a } 30^{\circ} \text { angle. They were then asked to raise their hips from the floor while keeping their shoulders }\end{array}$ & \\
\hline & down, with their body forming a straight line. & \\
\hline Roll-up & $\begin{array}{l}\text { The subjects were asked to lie down in the supine position. While they were breathing in, they were asked to } \\
\text { gather their arms in the air above their body and tuck their chin in toward their body in preparation for assum- } \\
\text { ing different postures. While they were breathing out, they were asked to roll up and lift their upper body } \\
\text { starting from their head to their back and their waist with their arms. They were then instructed to draw in or } \\
\text { contract their abdominal muscles. }\end{array}$ & \\
\hline One-leg raise & $\begin{array}{l}\text { The subjects were asked to lie down in the supine position. They were then instructed to perform an ADM } \\
\text { and then raise their right leg to the end range while keeping their knee extended. They were then instructed } \\
\text { to draw in or contract their abdominal muscles. }\end{array}$ & \\
\hline
\end{tabular}


were measured twice, with a 2-3 min interval, and the muscle thickness was analyzed from the collected images.

\section{Statistical analysis}

Data were analyzed with SPSS 17.0 and are presented as mean \pm standard deviation. A one-way ANOVA with an appropriate post-hoc test was used for group comparisons at rest and during each spinal stabilization maneuver. The significance level was set at $P<0.05$.

\section{RESULTS}

\section{MVIC and surface muscle activity during spinal stabilization exercises}

MVIC of the EO was significantly different between the groups $(P<0.05)$, but the RA muscle activity was similar among the groups at rest (Table 2). Post hoc analysis demonstrated a higher MVIC of the EO in the Pilates group than the controls. Interestingly, the surface muscle RA and EO activity was not significantly different between the groups during the ADM, bridging, rollup, and one-leg raise exercises (Tables 3-6).

Table 2. MVIC and deep abdominal muscle thickness at rest

\begin{tabular}{|c|c|c|c|c|c|c|}
\hline Measurement & Muscle & Pilates $(n=10)$ & Resistance $(n=10)$ & Control $(n=10)$ & $P$ & Posthoc \\
\hline Muscle activity (MVIC) & $\begin{array}{l}\text { RA } \\
\text { EO }\end{array}$ & $\begin{array}{l}336.40 \pm 223.27 \\
403.58 \pm 190.30\end{array}$ & $\begin{array}{l}317.85 \pm 246.63 \\
355.83 \pm 210.78\end{array}$ & $\begin{array}{l}299.96 \pm 216.58 \\
210.29 \pm 84.90\end{array}$ & $\begin{array}{l}0.778 \\
0.036\end{array}$ & $\begin{array}{c}\mathrm{NS} \\
\mathrm{PE}>\mathrm{CON}^{*}\end{array}$ \\
\hline Abdominal thickness $(\mathrm{mm})$ & $\begin{array}{l}\text { TrA } \\
10 \\
\text { EO }\end{array}$ & $\begin{array}{l}0.41 \pm 0.21 \\
1.03 \pm 0.27 \\
0.72 \pm 0.11\end{array}$ & $\begin{array}{l}0.36 \pm 0.11 \\
0.95 \pm 0.26 \\
0.56 \pm 0.11\end{array}$ & $\begin{array}{l}0.37 \pm 0.10 \\
0.79 \pm 0.79 \\
0.44 \pm 0.22\end{array}$ & $\begin{array}{l}0.712 \\
0.066 \\
0.002\end{array}$ & $\begin{array}{c}N S \\
N S \\
P E>\mathrm{CON}^{*},\end{array}$ \\
\hline
\end{tabular}

${ }^{*} P<0.05$.

MVIC, maximal voluntary isometric contraction; RA, rectus abdominis; EO, external oblique; $\operatorname{TrA}$, transversus abdominis; 10 , internal oblique; PE, pilates; RE, resistance; CON, control.

Table 3. Superficial muscle activity (\% MVIC) and deep abdominal muscle thickness during an abdominal drawing in maneuver

\begin{tabular}{|c|c|c|c|c|c|c|}
\hline Measurement & Muscle & Pilates $(n=10)$ & Resistance $(n=10)$ & Control $(n=10)$ & $P$ & Post hoc \\
\hline Muscle activity (\% MVIC) & $\begin{array}{l}\text { RA } \\
\text { EO }\end{array}$ & $\begin{array}{r}4.62 \pm 3.17 \\
14.04 \pm 9.90\end{array}$ & $\begin{array}{r}3.61 \pm 1.78 \\
13.56 \pm 7.31\end{array}$ & $\begin{array}{r}6.57 \pm 5.33 \\
12.90 \pm 8.17\end{array}$ & $\begin{array}{l}0.214 \\
0.703\end{array}$ & $\begin{array}{l}\text { NS } \\
\text { NS }\end{array}$ \\
\hline Abdominal thickness (mm) & $\begin{array}{l}\text { TrA } \\
10 \\
\text { EO }\end{array}$ & $\begin{array}{l}0.82 \pm 0.21 \\
1.34 \pm 0.32 \\
0.73 \pm 0.15\end{array}$ & $\begin{array}{l}0.65 \pm 0.12 \\
1.35 \pm 0.43 \\
0.67 \pm 0.14\end{array}$ & $\begin{array}{l}0.59 \pm 0.20 \\
0.10 \pm 0.19 \\
0.53 \pm 0.24\end{array}$ & $\begin{array}{l}0.022 \\
0.036 \\
0.052\end{array}$ & $\begin{array}{c}\mathrm{PE}>\mathrm{RE}, \mathrm{CON} \mathrm{N}^{*} \\
\mathrm{PE}, \mathrm{RE}>\mathrm{CON}^{*} \\
\mathrm{PE}>\mathrm{CON}^{*}\end{array}$ \\
\hline$\Delta$ Abdominal thickness $(\mathrm{mm})$ & $\begin{array}{l}\text { TrA } \\
\text { IO } \\
\text { EO }\end{array}$ & $\begin{array}{l}0.41 \pm 0.09 \\
0.31 \pm 0.21 \\
0.13 \pm 0.16\end{array}$ & $\begin{array}{r}0.29 \pm 0.14 \\
0.40 \pm 0.43 \\
-0.10 \pm 0.15\end{array}$ & $\begin{array}{r}0.22 \pm 0.17 \\
0.20 \pm 0.15 \\
-0.03 \pm 0.20\end{array}$ & $\begin{array}{l}0.015 \\
0.340 \\
0.019\end{array}$ & $\begin{array}{c}\mathrm{PE}>\mathrm{CON}^{*} \\
\mathrm{NS} \\
\mathrm{PE}>\mathrm{RE}^{*}\end{array}$ \\
\hline
\end{tabular}

${ }^{*} P<0.05$.

MVIC, maximal voluntary isometric contraction; RA, rectus abdominis; EO, external oblique; $\operatorname{Tr} A$, transversus abdominis; I0, internal oblique; $\triangle$ Abdominal thickness (mm), the change in abdominal muscle thickness between rest and stabilization exercises; PE, Pilates; RE, resistance; CON, control.

Table 4. Superficial muscle activity (\% MVIC) and deep abdominal muscle thickness during bridging exercise

\begin{tabular}{|c|c|c|c|c|c|c|}
\hline Measurement & Muscle & Pilates $(n=10)$ & Resistance $(n=10)$ & Control $(n=10)$ & $P$ & Post hoc \\
\hline Muscle activity (\% MVIC) & $\begin{array}{l}\text { RA } \\
\text { EO }\end{array}$ & $\begin{array}{l}24.35 \pm 7.68 \\
20.87 \pm 9.28\end{array}$ & $\begin{array}{l}27.05 \pm 8.18 \\
22.02 \pm 10.29\end{array}$ & $\begin{array}{l}34.56 \pm 12.45 \\
23.93 \pm 8.80\end{array}$ & $\begin{array}{l}0.768 \\
0.768\end{array}$ & $\begin{array}{l}\text { NS } \\
\text { NS }\end{array}$ \\
\hline Abdominal thickness (mm) & $\begin{array}{l}\text { TrA } \\
10 \\
\text { EO }\end{array}$ & $\begin{array}{l}0.76 \pm 0.26 \\
1.46 \pm 0.27 \\
0.82 \pm 0.18\end{array}$ & $\begin{array}{l}0.62 \pm 0.16 \\
1.52 \pm 0.38 \\
0.79 \pm 0.17\end{array}$ & $\begin{array}{l}0.52 \pm 0.14 \\
1.08 \pm 0.18 \\
0.67 \pm 0.24\end{array}$ & $\begin{array}{l}0.034 \\
0.004 \\
0.768\end{array}$ & $\begin{array}{c}\mathrm{PE}>\mathrm{CON}^{*} \\
\mathrm{PE}, \mathrm{RE}>\mathrm{CON}^{*} \\
\mathrm{NS}\end{array}$ \\
\hline$\Delta$ Abdominal thickness $(\mathrm{mm})$ & $\begin{array}{l}\text { TrA } \\
10 \\
\text { EO }\end{array}$ & $\begin{array}{l}0.32 \pm 0.25 \\
0.46 \pm 0.20 \\
0.13 \pm 0.21\end{array}$ & $\begin{array}{r}0.25 \pm 0.13 \\
0.57 \pm 0.20 \\
-0.05 \pm 0.24\end{array}$ & $\begin{array}{r}0.12 \pm 0.12 \\
0.22 \pm 0.18 \\
-0.06 \pm 0.13\end{array}$ & $\begin{array}{l}0.053 \\
0.002 \\
0.071\end{array}$ & $\begin{array}{c}\mathrm{NS} \\
\mathrm{PE}, \mathrm{RE}>\mathrm{CON}^{*} \\
\mathrm{NS}\end{array}$ \\
\hline
\end{tabular}

${ }^{*} P<0.05$.

MVIC, maximal voluntary isometric contraction; RA, rectus abdominis; EO, external oblique; TrA, transversus abdominis; IO, internal oblique; $\Delta$ Abdominal thickness (mm), the change in abdominal muscle thickness between rest and stabilization exercises; PE, Pilates; RE, resistance; CON, control. 


\section{Deep abdominal muscle thickness at rest and during spinal stabilization exercises}

Under resting conditions, $\operatorname{Tr} \mathrm{A}$ and $\mathrm{IO}$ muscle thicknesses were similar between the three groups (Table 2). However, EO muscle thickness was significantly different between the groups $(P<0.01)$. Post hoc analysis demonstrated a higher EO muscle thickness in Pilates group, compared to resistance and control group $(P<0.05)$.

During the ADM, the $\operatorname{Tr} A$ and IO muscle thicknesses were different between groups $(P<0.05)$, with a significantly greater thickness of both muscles observed in the Pilates group, compared to the resistance and control groups (Table 3). The difference in EO muscle thickness between Pilates group and control group did not reach statistical significance $(P=0.052)$; however, the EO muscle thickness in the Pilates group was higher than that of the control group $(P<0.05)$. In addition, the change in $\operatorname{Tr} A$ muscle thickness from rest was significantly greater in the Pilates group than the controls $(P<0.05)$, and the change in EO muscle thickness from rest was significantly greater in the Pilates group than the resistance group $(P<0.05$, Table 3$)$.

During bridging stabilization exercise, a significant between- group difference in overall $\operatorname{Tr} A$ muscle thickness was found $(P<0.05$, Table 4$)$, with post hoc analysis indicating a greater thickness in the Pilates group compared with the untrained controls. The IO muscle thickness was also significantly different between groups during bridging $(P<0.01)$, with the Pilates and resistance exercise groups demonstrating a larger IO muscle thickness relative to the controls. Similar findings were obtained when the data were calculated as a change from resting conditions. However, there was no difference in EO muscle thickness and the change of muscle thickness among the groups (Table 4).

The $\operatorname{Tr} A$ and EO muscle thicknesses were also found to be significantly different between groups during roll-up exercises $(P<0.05)$. Further post hoc analysis indicated that the $\operatorname{Tr} A$ was thicker in the Pilates group, relative to the controls, and the EO were thicker in the resistance group than the control group (Table 5). The change in $\operatorname{Tr} A$ muscle thickness from rest was also greater in the Pilates group compared with the control group (Table 5).

Similar to the other spinal stabilization exercises, significant between-group differences were found for $\operatorname{Tr} A$ and IO muscle thicknesses during one-leg raises $(P<0.05$, Table 6$)$. Post hoc analysis

Table 5. Superficial muscle activity (\% MVIC) and deep abdominal muscle thickness during roll-up exercise

\begin{tabular}{|c|c|c|c|c|c|c|}
\hline Measurement & Muscle & Pilates $(n=10)$ & Resistance $(n=10)$ & Control $(n=10)$ & $P$ & Post hoc \\
\hline Muscle activity (\% MVIC) & $\begin{array}{l}\text { RA } \\
\text { EO }\end{array}$ & $\begin{array}{l}27.84 \pm 16.50 \\
28.90 \pm 14.87\end{array}$ & $\begin{array}{l}30.01 \pm 8.67 \\
43.34 \pm 63.06\end{array}$ & $\begin{array}{l}36.91 \pm 8.25 \\
28.16 \pm 16.28\end{array}$ & $\begin{array}{l}0.217 \\
0.617\end{array}$ & $\begin{array}{l}\text { NS } \\
\text { NS }\end{array}$ \\
\hline Abdominal thickness (mm) & $\begin{array}{l}\text { TrA } \\
10 \\
\text { EO }\end{array}$ & $\begin{array}{l}0.71 \pm 0.18 \\
1.44 \pm 0.31 \\
0.79 \pm 0.20\end{array}$ & $\begin{array}{l}0.57 \pm 0.20 \\
1.48 \pm 0.45 \\
0.88 \pm 0.28\end{array}$ & $\begin{array}{l}0.48 \pm 0.15 \\
1.14 \pm 0.25 \\
0.60 \pm 0.23\end{array}$ & $\begin{array}{l}0.024 \\
0.074 \\
0.037\end{array}$ & $\begin{array}{c}\mathrm{PE}>\mathrm{CON}^{*} \\
\mathrm{NS} \\
\mathrm{RE}>\mathrm{CON}^{*}\end{array}$ \\
\hline$\Delta$ Abdominal thickness (mm) & $\begin{array}{l}\text { TrA } \\
\text { IO } \\
\text { EO }\end{array}$ & $\begin{array}{l}0.30 \pm 0.17 \\
0.40 \pm 0.21 \\
0.24 \pm 0.27\end{array}$ & $\begin{array}{l}0.21 \pm 0.18 \\
0.53 \pm 0.25 \\
0.11 \pm 0.24\end{array}$ & $\begin{array}{l}0.11 \pm 0.11 \\
0.34 \pm 0.24 \\
0.12 \pm 0.24\end{array}$ & $\begin{array}{l}0.033 \\
0.219 \\
0.330\end{array}$ & $\begin{array}{c}\mathrm{PE}>\mathrm{CON}^{*} \\
\mathrm{NS} \\
\mathrm{NS}\end{array}$ \\
\hline
\end{tabular}

${ }^{*} P<0.05$.

MVIC, maximal voluntary isometric contraction; RA, rectus abdominis; EO, external oblique; TrA, transversus abdominis; IO, internal oblique; $\triangle$ Abdominal thickness (mm), the change in abdominal muscle thickness between rest and stabilization exercises; PE, Pilates; $\mathrm{RE}$, resistance; $\mathrm{CON}$, control.

Table 6. Superficial muscle activity (\% MVIC) and deep abdominal muscle thickness during one-leg raise exercise

\begin{tabular}{|c|c|c|c|c|c|c|}
\hline Measurement & Muscle & Pilates $(n=10)$ & Resistance $(n=10)$ & Control $(n=10)$ & $P$ & Post hoc \\
\hline Muscle activity (\% MVIC) & $\begin{array}{l}\text { RA } \\
\text { EO }\end{array}$ & $\begin{array}{r}9.10 \pm 4.92 \\
16.92 \pm 8.29\end{array}$ & $\begin{array}{l}5.84 \pm 2.86 \\
9.42 \pm 6.23\end{array}$ & $\begin{array}{l}10.17 \pm 7.92 \\
15.93 \pm 8.90\end{array}$ & $\begin{array}{l}0.219 \\
0.088\end{array}$ & $\begin{array}{l}\text { NS } \\
\text { NS }\end{array}$ \\
\hline Abdominal thickness (mm) & $\begin{array}{l}\text { TrA } \\
\text { IO } \\
\text { EO }\end{array}$ & $\begin{array}{l}0.90 \pm 0.25 \\
1.42 \pm 0.17 \\
0.85 \pm 0.27\end{array}$ & $\begin{array}{l}0.66 \pm 0.19 \\
1.42 \pm 0.32 \\
0.88 \pm 0.23\end{array}$ & $\begin{array}{l}0.61 \pm 0.22 \\
1.16 \pm 0.26 \\
0.68 \pm 0.30\end{array}$ & $\begin{array}{l}0.017 \\
0.049 \\
0.210\end{array}$ & $\begin{array}{c}\mathrm{PE}>\mathrm{RE}, \mathrm{CON}{ }^{*} \\
\mathrm{PE}, \mathrm{RE}>\mathrm{CON}^{*} \\
\mathrm{NS}\end{array}$ \\
\hline$\Delta$ Abdominal thickness $(\mathrm{mm})$ & $\begin{array}{l}\text { TrA } \\
\text { IO } \\
\text { EO }\end{array}$ & $\begin{array}{l}0.49 \pm 0.31 \\
0.39 \pm 0.28 \\
0.24 \pm 0.27\end{array}$ & $\begin{array}{l}0.30 \pm 0.16 \\
0.47 \pm 0.31 \\
0.11 \pm 0.24\end{array}$ & $\begin{array}{l}0.24 \pm 0.19 \\
0.37 \pm 0.24 \\
0.12 \pm 0.24\end{array}$ & $\begin{array}{l}0.058 \\
0.666 \\
0.443\end{array}$ & $\begin{array}{l}\text { NS } \\
\text { NS } \\
\text { NS }\end{array}$ \\
\hline
\end{tabular}

${ }^{*} P<0.05$.

MVIC, maximal voluntary isometric contraction; RA, rectus abdominis; EO, external oblique; TrA, transversus abdominis; IO, internal oblique; $\Delta$ Abdominal thickness (mm), the change in abdominal muscle thickness between rest and stabilization exercises; PE, Pilates; RE, resistance; CON, control. 
demonstrated that the TrA thickness was greater in the Pilates group, whereas the IO thickness was greater in the Pilates and resistance exercise groups, when compared with the controls (Table 6). However, there was no difference in EO muscle thickness and the change of muscle thickness among the groups (Table 6).

\section{DISCUSSION}

In the present study, we compared surface muscle activity and deep muscle thickness in experienced Pilates and resistance exercise instructors, relative to control subjects, during relaxation and spinal stabilization exercise. We found that the surface muscle activity did not depend on exercise experience or proficiency when performing exercise for spinal stabilization. However, the thickness and activation of the deep muscles during stabilization exercise were greater in the Pilates and resistance exercise groups compared to the control group. In particular, the $\operatorname{Tr} A$ was most effectively recruited in the Pilates group, whereas the IO was recruited in a similar manner in the resistance and Pilates exercise groups.

EMG has been the most widely used instrument for the study of muscle activation during exercise (Monfort-Pañego et al., 2009). Interestingly, the RA muscle was generally activated to a greater extent in the control group, although not with statistical significance. These results suggest that the control subjects may recruit their surface muscles to a greater extent because they were not familiar with the exercises or the necessary breathing and had a lower MVIC, when compared to the Pilates and resistance exercise groups. It is possible that the overall lack of statistical significance based on exercise experience or proficiency, and the absence of a between-group difference in the surface muscle activation, is because spinal stabilization exercises are focused more on deep muscle activation.

Critchley et al. (2011) reported that the IO became significantly thicker during the imprint, in which the belly button is sucked in toward the spine while breathing out in a supine position, in the group that was experienced with resistance exercise, according to the ultrasound scan. They also reported that the group with Pilates experience showed decreased IO thickness but increased $\operatorname{Tr} A$ thickness. During the ADM that was used in this study, which is used to imprint, the ultrasound-determined $\operatorname{Tr} \mathrm{A}$, IO, and EO muscle thickness, as well as the change in $\operatorname{Tr} A$ muscle thickness, were greater in the Pilates group than the control group. The resistance exercise group only showed an IO muscle thickness that was greater than that of the control group. Critchley previously reported that the $\operatorname{Tr} A$ was thicker during an ADM with pelvic floor contraction than without pelvic floor contraction (Critchley, 2002). As breathing during Pilates activates the deep muscles by contracting the pelvic floor, while sucking in the belly button during exhalation, the Pilates group consisted of subjects who were already familiar with the necessary breathing and postures that activate the deep muscles. This result is consistent with the findings of Endleman and Critchley (2008) which suggested that people experienced and inexperienced in Pilates showed a different degree of TrA activation in similar postures. Moreover, the inexperienced subjects may not have been able to accurately perform ADM because they were not familiar with it. However, the EO muscle showed significant differences in surface muscle activity and muscle thickness between the groups. These results suggested that the relationship in the EO muscle between surface muscle activity and muscle thickness is much weaker, and ultrasound-measured thickness change cannot be confidently used as a gauge of activity in the $\mathrm{EO}$ muscle.

In bridging, the body is kept straight a position that is difficult for inexperienced people (i.e., control group) or people with back pain (Endleman and Critchley, 2008). Stevens et al. (2007) reported that IO activity was increased to a greater extent during bridging in a stabilization exercise group compared to a control group. The results of the current study are consistent with these results, and show that the TrA and IO thicknesses in the Pilates and resistance exercise groups were greater during bridging relative to controls. This increase in the deep muscle thickness may occur because the Pilates and resistance exercise subjects were familiar with bridging.

Interestingly, roll-up is similar to crunch which is usually performed as a resistance exercise, our results show that the TrA muscle thickness was the highest in the Pilates group, compared with the other 2 groups. As the basic concept of Pilates is stabilization of the spine (Gladwell et al., 2006; Muscolino and Cipriani, 2004), Pilates trains a person to contract the TrA and IO in all postures. In addition, the subjects in the Pilates group were experienced with crunches because crunches are similar to the half rollups used in Pilates However, the IO in the study was the highest in the resistance exercise group than the other 2 groups, even though the difference was not statically significant. Moreover, the $\mathrm{EO}$ in the resistance exercise group was significantly thicker than that of the control group. This result indicates that hypotrophy was observed in a resistance exercise in which a heavy load was lifted, and it stabilized the lumbar spine. Furthermore, elite weightlifters have been reported to have thicker IOs than average 
people because the IO works with the EO to control external loads and to transfer the load between the thorax and the pelvis (Sitilertpisan et al., 2011). Therefore, the IO was considered to have been more recruited than the $\operatorname{Tr} A$ in the crunch because the subjects were trained to use their IO by lifting a load. However, the results of $\mathrm{EO}$ muscle thickness and activity showed the difference. This inconsistency of results between EMG and muscle thickness proved that ultrasound scanning cannot be used as a valid measure of activity of the $\mathrm{EO}$ muscle.

Overall, most Pilates postures are focused on the abdominal muscles. Therefore, even during exercises for the arms or legs, individuals have to monitor their breathing and assume the postures, while simultaneously drawing in the belly button and contracting the pelvic floor. In this regard, during one-leg raise exercises, a greater $\operatorname{Tr} A$ thickness was found in the Pilates group than in the resistance exercise and control groups. In contrast, the IO thickness of the Pilates and resistance exercise groups were both larger than the control group during one-leg raises. The subjects in the Pilates group likely showed a greater change in the $\operatorname{Tr} A$ thickness because, as mentioned above, they are trained to contract their abdominal muscles while breathing. The increased IO thickness in the resistance exercise group during one-leg raise may be due to the training of the subjects to contract their IO and EO while exercising, even if the postures did not involve any load.

In conclusion, exercise experience and proficiency in Pilates or resistance exercise did not affect the recruitment of surface muscles during stabilization exercises. However, the thickness of the deep muscles was significantly different between the groups during the exercises, and the Pilates group showed marked changes in the TrA and IO muscle thickness. This is presumably because Pilates training teaches individuals to contract the abdominal muscles while maintaining balanced postures. The IO muscle thickness was not significantly different between the Pilates and resistance groups, although the IO muscle thickness of both trained groups was larger than that of the controls during stabilization exercises. The greater reliance of the resistance exercise-trained subjects on the IO may be because resistance exercise stabilizes the lumbar spine by working with the global muscles (e.g., EO) against an external load and with hypertrophy (Sitilertpisan et al., 2011). Overall, our findings suggest that Pilates and resistance exercise have a similar effect on spinal stabilization because of the activation and recruitment of deep muscles.

This study had a limited number of subjects and did not evaluate postures that subjects in the resistance exercise group were familiar with, and therefore, further studies on these factors are re- quired.

\section{CONFLICTS OF INTEREST}

No potential conflict of interest relevant to this article was reported

\section{REFERENCES}

Adams MA, Roughley PJ. What is intervertebral disc degeneration and what causes it? Spine 2006;31(18):2151-2161.

Bergmark A. Stability of the lumbar spine. A study in mechanical engineering. Acta Orthop Scand Suppl 1989;230:1-54.

Bernado LM. The effectiveness of Pilates training in healthy adults: an appraisal of the research literature. J Body Mov Ther 2007;11:106-110.

Critchley D. Instructing pelvic floor contraction facilitates transversus abdominis thickness increase during low-abdominal hollowing. Physiother Res Int 2002;7(2):65-75.

Critchley DJ, Pierson Z, Battersby G. Effect of pilates mat exercise and conventional exercise programmes on transverses abdominis and obliquus abdominis activity: pilot randomized trial. Man Ther 2011; 16(2):183-189.

da Fonseca JL, Magini M, de Freitas TH. Laboratory gait analysis in patients with low back pain before and after a Pilates intervention. J Sport Rehabil 2009;18(2):269-182.

Ekstrom RA, Donatelli RA, Carp KC. Electromyographic analysis of core trunk, hip, and thigh muscles during 9 rehabilitation exercises. J Orthop Sports Phys Ther 2007;37(12):754-762.

Endleman L, Critchley DJ. Transversus abdominis and obliquus internus activity during pilates exercise: measurement with ultrasound scanning. Arch Phys Med Rehabil 2008;80(11):2205-2212.

Gladwell V, Head S, Haggar M, Beneke R. Does a program of pilates improve chronic non-specific a low back pain? J Sport Rehabil 2006;15: 338-350.

Hayden JA, van Tulder MW, Tomlinson G. Systematic review: strategies for using exercise therapy to improve outcomes in chronic low back pain. Ann Intern Med 2005;142(9):776-785.

Hibbs AE, Thompson KG, French DN, Hodgson D, Spears IR. Peak and average rectified EMG measures: which method of data reduction should be used for assessing core training exercises? J Electromyogr Kinesiol 2011;21(1):102-111.

Hodges PW, Moseley GL. Pain and motor control of the lumbopelvic region: effect and possible mechanisms. J Electromyogr Kinesiol 2003; 13(4):361-370.

Hodges PW, Gandervia SC. Activation of the human diaphragm during a 
repetitive postural task. J Physiol 2000;522:165-175.

Jeong J, Kim K, Kim J. Age related analysis of ultrasound images of normal skeletal muscle. J Korean Acad Univ Trained Phys Ther 2006; 13(1):47-53.

John EK, Beith ID. Can activity within the external abdominal oblique be measured using real-time ultrasound imaging? Clin Biomech (Bristol, Avon) 2007;22(9):972-979.

Macedo LG, Maher CG, Latimer J, McAuley JH. Motor control exercise for persistent, nonspecific low back pain: a systematic review. Phys Ther 2009;89(1):9-25.

McMeeken JM, Beith ID, Newham DJ, Milligan P, Critchley DJ. The relationship between EMG and change in thickness of transversus abdominis. Clin Biomech (Bristol, Avon) 2004;19(4):337-342.

Monfort-Pañego M, Vera-García FJ, Sánchez-Zuriaga D, Sarti-Martínez MA. Electromyographic studies in abdominal exercises: a literature synthesis. J Manipulative Physiol Ther 2009;32(3):232-244.

Muscolino JE, Cipriani S. Pilates and the "Powerhouse"-II. J Body Mov Ther 2004;8:122-130.

$\mathrm{Ng} J$ K, Kippers V, Richardson CA. Muscle fibre orientation of abdominal muscles and suggested surface EMG electrode positions. Electromyogr Clin Neurophysiol 1998:38(1):51-58.

Sertpoyraz F, Eyigor S, Karapolat H, Capaci K, Kirazli Y. Comparison of isokinetic exercise versus standard exercise training in patients with chronic low back pain: a randomized controlled study. Clin Rehabil 2009;23(3):238-247.

Sitilertpisan P, Pirunsan U, Puangmali A, Ratanapinunchai J, Kiatwattanacharoen S, Neamin J, Laskin JJ. Comparison of lateral abdominal muscle thickness between weightlifters and matched controls. Phys Ther Sport 2011;12(4):171-174.

Springer PJ, Corbett C, Davis N. Enhancing evidence-based practice through collaboration. J Nurs Adm 2006:36(11):534-537.

Sternlicht E, Rugg S. Electromyographic analysis of abdominal muscle activity using portable abdominal exercise devices and a traditional crunch. J Strength Cond Res 2003;17(3):463-468.

Stevens VK, Coorevits PL, Bouche KG, Mahieu NN, Vanderstraeten GG, Danneels LA. The influence of specific training on trunk muscle recruitment patterns in healthy subjects during stabilization exercises. Man Ther 2007;12(3):271-279.

Teyen DS, Miltenberger CE, Deiters HM, DelToro YM, Pulliam JN, Childs JD, Boyles RE, Flynn TW. The use of ultrasound imaging of the abdominal drawing in maneuver in subjects with low back pain. J Orthop Sports Phys Ther 2005;35(6):346-355.

Waddell G, Somerville D, Henderson I, Newton M. Objective clinical evaluation of physical impairment in chronic low back pain. Spine 1992;17(6):617-628. 